\title{
Characterisation of T-DNA loci and vector backbone sequences in transgenic wheat produced by Agrobacterium-mediated transformation
}

\author{
Huixia Wu - Caroline A. Sparks $\cdot$ Huw D. Jones
}

Published online: 31 March 2007

(C) Springer Science+Business Media B.V. 2007

\section{Erratum to: Mol Breeding (2006) 18:195-208 \\ DOI 10.1007/s11032-006-9027-0}

The Acknowledgements section was missing in the original publication. The section is printed below.

Acknowledgements Rothamsted Research receives grantaided support from the Biotechnology and Biological Sciences Research Council UK. HW was funded by the Department of Food and Rural Affairs UK. We thank Drs. Lucia Primavesi and Alison Huttly for critically reading the manuscript.

The online version of the original article can be found at http://dx.doi.org/10.1007/s11032-006-9027-0

H. Wu · C. A. Sparks · H. D. Jones $(\bowtie)$

CPI Division, Rothamsted Research, Harpenden,

Hertfordshire AL5 2JQ, UK

e-mail: huw.jones@bbsrc.ac.uk 